\title{
Vulcanization of Synthetic Rubbers by the Peachey Process $^{1}$
}

\section{By Norman Bekkedahl, Fred A. Quinn, Jr., and Elmer W. Zimmerman}

\begin{abstract}
The Peachey process, which vulcanizes natural rubber by subjecting it alternately to sulfur dioxide and hydrogen sulfide gases, has been found to vulcanize the more common synthetic rubbers. The polymers studied were natural rubber, GR-S, GR-M, GR-I, GR-A, Hycar OR-15, Hycar OR-25, Hycar OS-10, Hycar OS-20, and Hycar OS-30. Good cures were obtained with all of the polymers except GR-M. None of the synthetic rubbers cured any faster than natural rubber. The nitrile and the styrene copolymers of butadiene cured at about the same rate or somewhat slower. GR-I required roughly 50 times as long as natural rubber for an equivalent cure, and GR $\mathrm{M}$ required even longer.
\end{abstract}

\section{Introduction}

The Peachey process, which has been used to vulcanize natural rubber by subjecting the rubber alternately to sulfur dioxide and hydrogen sulfide gases $[1,2,4,6,7],{ }^{2}$ has now been applied to synthetic rubbers. This communication describes the results of an investigation initiated recently by McPherson [5]. The polymers studied include natural rubber, GR-S (butadiene-styrene copolymer), GR-M (polychloroprene rubber similar to Neoprene-GN), GR-I (isobutene-isoprene copolymer, or Butyl rubber), GR-A (butadiene-acrylonitrile copolymer, or nitrile rubber), Hycar OR-15 (similar to GR-A), Hycar OR-25 (lower acrylonitrile content than the OR-15), Hycar OS-10 (butadiene-styrene copolymer having a considerably higher styrene content than GR-S), Hycar OS-20 and Hycar OS-30 (both similar to GR-S with the exception that the OS-20 contains little or no fatty acid).

\section{Experimental Procedure}

The rubbers tested were sheeted as thinly as practicable, usually from 0.5 to $1 \mathrm{~mm}$, by means of a laboratory rubber mill, and strips approximately 1.75 by $13 \mathrm{~cm}$ were cut from the sheets. These strips (usually four to six at a

\footnotetext{
1 This paper was presented at the 112th national meeting of the American Chemical Society held in New York City, September 15 to 19, 1947.

${ }^{2}$ Figures in brackets indicate the literature references at the end of this paper.
}

time) were placed on a long piece of heavy-gage galvanized wire screening that was inserted in a 25-mm diameter glass tube approximately $1 \mathrm{~m}$ in length, each end being equipped with a groundglass joint. A triple inlet tube was connected to one end so that the gases, sulfur dioxide, air, and hydrogen sulfide, could be admitted separately. A single outlet tube at the opposite end led the unabsorbed gases first through a 20 percent solution of sodium hydroxide, then through a saturated solution of bromine in water, and finally through a dilute solution of sodium hydroxide in order to trap any of the remaining gases, including bromine vapors.

Except for the initial series of tests, which will be discussed later, all of the test strips were exposed to the vulcanizing gases for 5-minute cycles, the number of cycles being varied from one to as many as 128 in an effort to determine the conditions for optimum cure for each of the various synthetics tested. A single cycle consisted of a 5-minute exposure to sulfur dioxide, a brisk 10-second sweep of air to remove the sulfur dioxide gas not absorbed by the samples, and a 5-minute exposure to hydrogen sulfide, followed by another brisk sweep of air.

In all of the experiments a separate set of samples was used for each of the various numbers of cycles indicated, i. e., one set of samples was inserted into the tube, exposed for one cycle, and removed; a different set was exposed for two cycles 
and removed, etc., until all of the desired number of cycles were completed. The samples were then placed in a vacuum oven at room temperature for 3 hours to remove all uncombined gases and also the water vapor that is formed in the vulcanizing reaction, and were then weighed to determine the weight increase, which was assumed to be caused by the added sulfur.

The extent of cure of each strip was qualitatively evaluated by hand-stretching. Some of the samples from each run were then quantitatively analyzed to determine how much sulfur had actually combined with the polymer. The difference between the percentage increase in weight and the combined sulfur was assumed to be free sulfur. Chemical analyses on a number of the samples for free sulfur indicated this assumption to be correct.

\section{Results of Experiments}

Before beginning the actual vulcanization studies, strips of each of the rubbers to be tested were submitted to a 16-hour exposure to sulfur dioxide gas; another set of samples was similarly exposed to hydrogen sulfide gas for the same length of time. The average increase in weight during this treatment was 0.2 percent, indicating that there was very little, if any, chemical addition of the gases to the rubber.

An initial series of tests was made to determine the most practical period of exposure of the rubber to each of the two gases. Natural rubber was used for this determination. In addition to the pure ribbed smoked sheet, three batches of smoked sheet containing various combinations of fillers and accelerators (see table 1) were exposed to determine whether or not these combinations would cause a change in the rate of vulcanization. Single cycles of $1.25,2.5,5,10$, and 20 minutes, respectively, were run. A study of the curve of the percent increase in weight plotted against the duration of the cycle (fig. 1) shows that the longer times of exposure to the gases in a given cycle vulcanize a sample of rubber in a smaller number of cycles, but that the sulfur can be added in less total time using shorter cycles. Extremely short cycles, however, waste vulcanizing gases and also do not give time for the gases to penetrate into the interior of the rubber samples. As a compromise it was decided to use 5-minute cycles for the experiments to be described here. The numerical

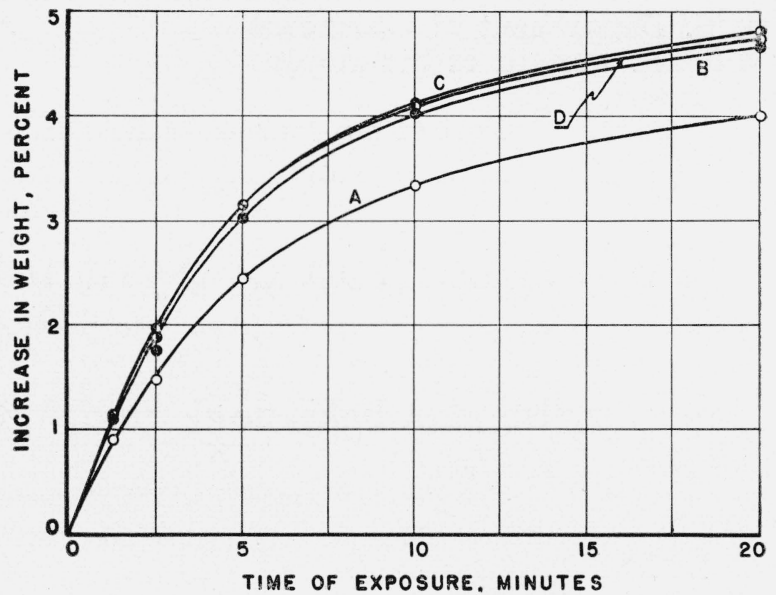

FIGURE 1. Increase in weight of samples of compounded natural rubber plotted as a function of the time of exposure to sulfur dioxide and to hydrogen sulfide for one cycle of operation.

The letters representing the curves refer to the compounding formulas given in table 1. Data from which these curves were prepared are given in table 2 .

values for these tests are given in table 2 . It will be noted that compounds $B, C$, and $D$ effected a significantly greater absorption of sulfur than $A$ (rubber alone), but that $C$ and $D$ produced no noticeable advantage over $B$. From the results of a repetition of this test, in which the samples were placed in reverse order in the tube, changing in effect the direction of flow of the gases with respect to the samples, it has been shown that the

TABLE 1. Compounding formulas

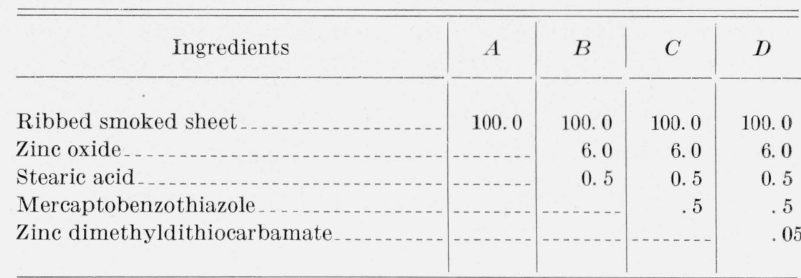

TABLe 2. Vulcanization for one cycle

\begin{tabular}{|c|c|c|c|c|c|}
\hline \multirow{2}{*}{ Type of polymer } & \multirow{2}{*}{ Duration of cycle } & \multicolumn{4}{|c|}{ Weight increases } \\
\hline & & $A^{1}$ & $B^{1}$ & $C^{1}$ & $D^{\perp}$ \\
\hline Natural _.. & $\left\{\begin{array}{l}\min \\
1.25 \\
2.5 \\
5 \\
10 \\
20\end{array}\right.$ & $\begin{array}{c}\text { Percent } \\
0.90 \\
1.47 \\
2.44 \\
3.34 \\
3.99\end{array}$ & $\begin{array}{c}\text { Percent } \\
1.10 \\
1.76 \\
3.02 \\
4.02 \\
4.66\end{array}$ & $\begin{array}{c}\text { Percent } \\
1.10 \\
1.88 \\
3.14 \\
4.13 \\
4.82\end{array}$ & $\begin{array}{r}\text { Percent } \\
\text { 1. } 14 \\
\text { 1. } 97 \\
3.15 \\
4.10 \\
4.75\end{array}$ \\
\hline
\end{tabular}

1 For compounding formulas, see table 1. 
position of the sample in the reaction tube does not affect the percentage weight increase.

In table 3 are summarized the data obtained from all of the synthetic rubbers and natural rubber studied. The increase in weight is based on the weight of the original sample. The combined sulfur is also computed on this basis and therefore represents the parts of combined sulfur per hundred parts of original polymer. The extent of cure was estimated by hand-stretching the individual specimens and observing the rate and degree of recovery. It is believed that the optimum cure, as indicated for each type of rubber, represents the vulcanizate that has the highest tensile strength.

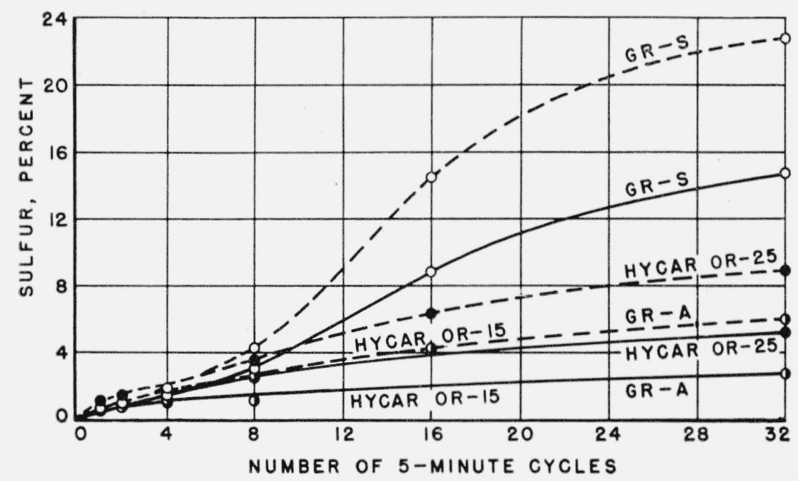

Figure 2. Percentage of sulfur added to $G R-S, G R-A$, Hycar OR-15, and Hycar OR-25 rubber samples plotted as a function of the number of 5-minute cycles of exposure to the gases of the Peachey process.

The solid lines indicate combined sulfur as determined by chemical analysis, and the broken lines indicate the total sulfur as determined by weight increase of the sample.

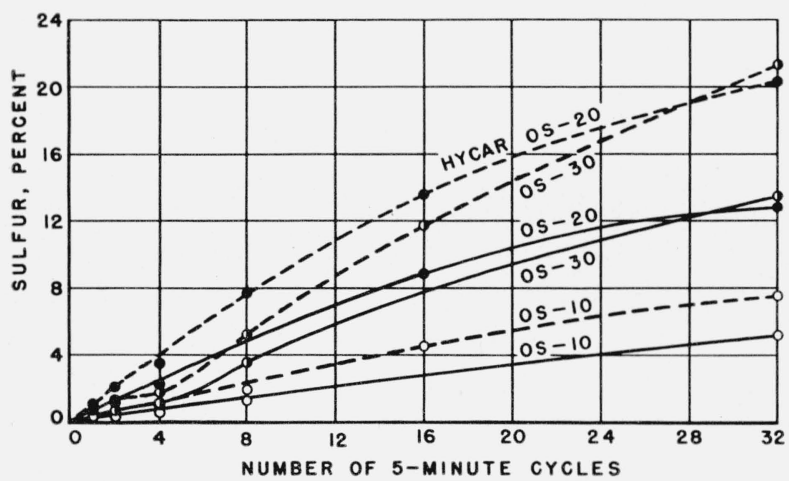

Figure 3. Percentage of sulfur added to Hycar OS-10, Hycar OS-20, and Hycar OS-30 rubber samples plotted as a function of the number of 5-minute cycles of exposure to the gases of the Peachey process.

The solid lines indicate combined surfur as determined by chemical anal ysis, and the broken lines indicate the total sulfur as determined by weight increase of the sample.
Figures 2 and 3 show in graphical form the data obtained from the butadiene-type polymers. All of these rubbers were run simultaneously. The solid lines indicate the amount of combined sulfur, and the broken lines represent the total sulfur. Figure 4 shows similar results for GR-I and GR-M synthetic rubbers. These polymers were run separately from the others because of their extremely low rate of cure. The results obtained from vulcanizing natural rubber are shown on this same graph for comparison.

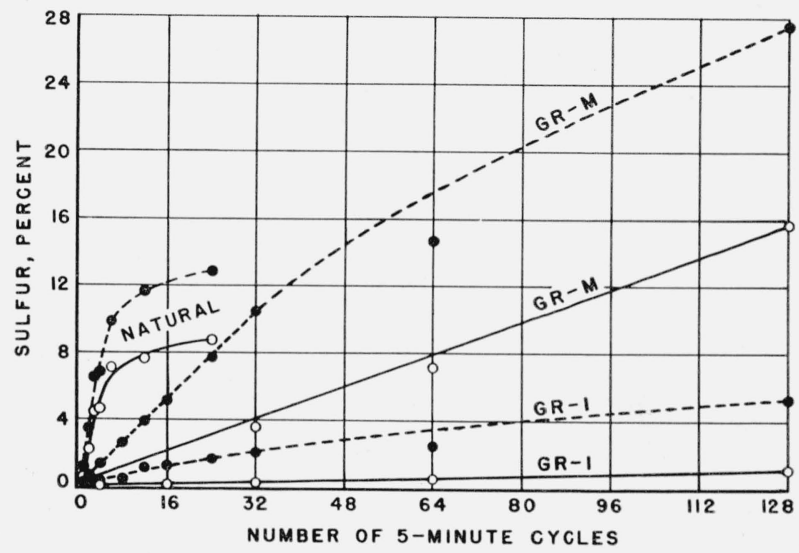

Figure 4. Percentage of sulfur added to $G R-M, G R-I$, and natural rubber samples plotted as a function of the number of 5-minute cycles of exposure to the gases of the Peachey process.

The solid lines indicate combined sulfur as determined by chemical anal ysis, and the broken lines indicate the total sulfur, as determined by weight increase of the sample.

A confirmatory experiment was performed in which natural rubber and all of the synthetic polymers, with the exception of GR-I and GR-M, were vulcanized simultaneously for $4,8,16$, and 32 cycles, respectively. The increases in weight agreed so closely with those obtained in the previous runs that it was thought unnecessary to run chemical analyses for the amount of combined sulfur or to tabulate the additional data.

As a matter of interest, the vulcanized pure ribbed smoked sheet specimens described in table 2 were subjected to two physical tests, namely, stress at $15 \mathrm{~kg} / \mathrm{cm}^{2}(213 \mathrm{psi})$ and permanent set. Each group of similar degrees of vulcanization $(1.25,2.5,5,10$, and 20 minutes) contained four strips, two of which had been eut longitudinal to the direction of passage of the rubber between the mixing rolls of the mill and two of which were cut 
TABLE 3. Vulcanizations for various numbers of cycles

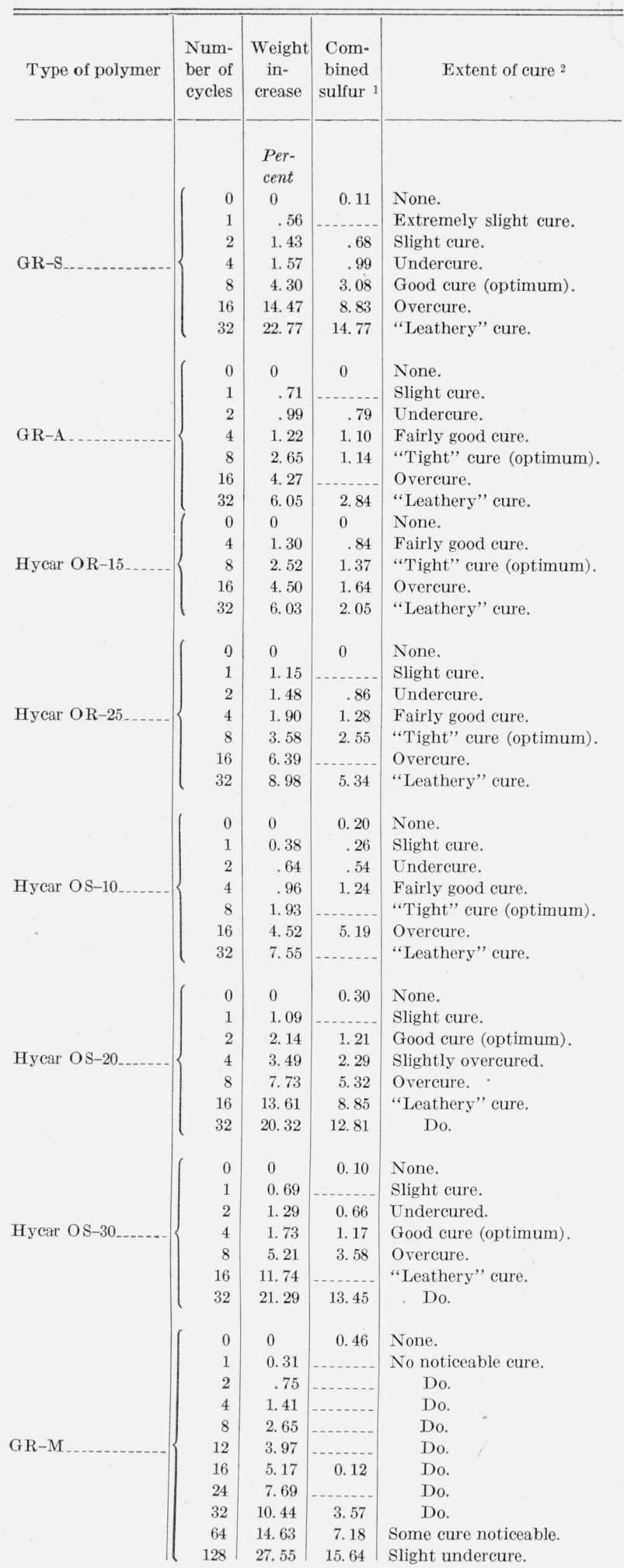

TABLE 3. Vulcanizutions for various numbers of cyclesContinued

\begin{tabular}{|c|c|c|c|c|}
\hline Type of polymer & $\begin{array}{l}\text { Num- } \\
\text { ber of } \\
\text { cycles }\end{array}$ & $\begin{array}{l}\text { Weight } \\
\text { in- } \\
\text { crease }\end{array}$ & $\begin{array}{c}\text { Com- } \\
\text { bined } \\
\text { sulfur } 1\end{array}$ & Extent of cure ${ }^{2}$ \\
\hline \multirow{12}{*}{ GR-I... } & & $\begin{array}{l}\text { Per- } \\
\text { cent }\end{array}$ & & \multirow{20}{*}{$\begin{array}{l}\text { None. } \\
\text { No noticeable cure. } \\
\text { Do. } \\
\text { Do. } \\
\text { Do. } \\
\text { slight cure. } \\
\text { Do. } \\
\text { Undercure. } \\
\text { Do. } \\
\text { Slight undercure. } \\
\text { Good cure (optimum). } \\
\text { None. } \\
\text { Appreciable cure. } \\
\text { Good cure (optimum). } \\
\text { Slight overcure. } \\
\text { Overcure. } \\
\text { Greatly overcured. } \\
\text { "Leathery" cure. } \\
\text { Do. }\end{array}$} \\
\hline & 0 & 0 & 0 & \\
\hline & 1 & 0.13 & & \\
\hline & 2 & .24 & & \\
\hline & 4 & .39 & 0.10 & \\
\hline & 9 & .55 & & \\
\hline & 12 & 1. 19 & & \\
\hline & 16 & 1. 23 & 0.12 & \\
\hline & 24 & 1. 77 & & \\
\hline & 32 & 2. 13 & 0.22 & \\
\hline & 64 & 2. 45 & .51 & \\
\hline & 128 & 5. 30 & 1.12 & \\
\hline \multirow{8}{*}{ Natural... } & 0 & 0 & 0 & \\
\hline & 1 & 1. 22 & 0.64 & \\
\hline & 2 & 3. 52 & 2.31 & \\
\hline & 3 & 6. 60 & 4. 55 & \\
\hline & 4 & 6. 95 & 4.78 & \\
\hline & 6 & 9.98 & 7.20 & \\
\hline & 12 & 11. 79 & 7.76 & \\
\hline & 24 & 12. 98 & 8.83 & \\
\hline
\end{tabular}

${ }^{1}$ Based on parts per hundred parts of polymer.

${ }^{2}$ Estimated by hand-stretching.

transverse to the direction of milling. After determining the cross-sectional area of each strip, the proper-sized dead weight was hung on the strip and the elongation between two gage marks was measured at the end of 1 minute. The weight was then allowed to continue hanging on the sample for an additional 4 minutes, after which time it was removed and the sample allowed to relax for 1 minute. The distance between the gage marks was again measured, and from this figure the permanent set was calculated. The results of these physical tests are summarized in table 5 and shown graphically in figure 5 .

Another interesting conclusion may be drawn from the results. The amount of combined sulfur in the optimum cures for natural rubber and for all of the synthetics, with the exception of GR-M, is between 1 and 3 percent (see table 4 ). This agrees very well with Peachey's conclusion that an optimum cure is attained in natural rubber by his process when a coefficient of vulcanization of 2.0 to 2.5 is attained $[6,7]$. The natural rubber and all of the synthetic rubbers investigated, with the exception of GR-I and GR-M, were also vulcanized to a "leathery" state, and to vulcanizing coefficients as high as 3 to 15 . At these higher 


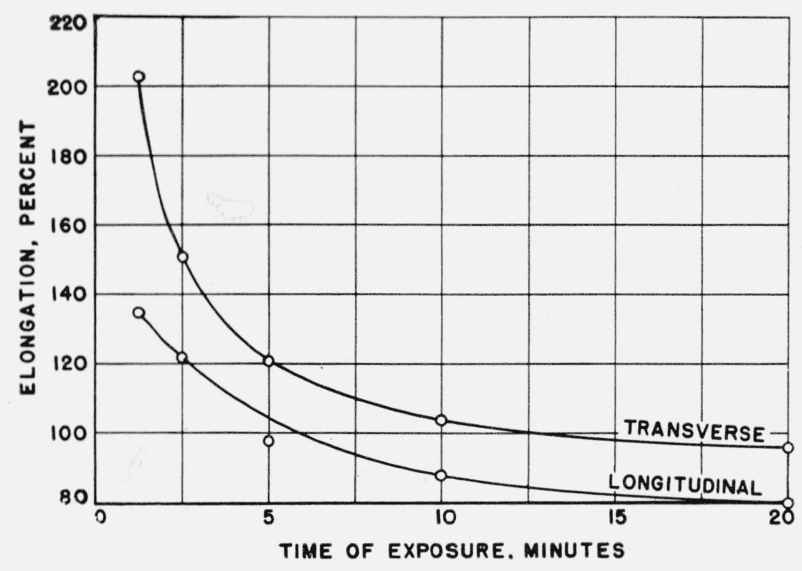

Figure 5. Elongation at stress of $15 \mathrm{~kg} / \mathrm{cm}^{2}$ (213 $\mathrm{psi}$ ) for natural rubber samples under different degrees of cure.

For some of the samples the stresses were measured longitudinally and others transversely to the direction of passage between the mixing rolls.

degrees of vulcanization there was quite a large amount of free sulfur deposited on the surface of the rubber. No attempt was made to continue toward a higher degree of vulcanization. St. Reiner [8], however, did continue the reaction further and claims that hard rubber can be produced from natural rubber by this process.

TABLE 4. Optimum cures from table 3

\begin{tabular}{|c|c|c|c|}
\hline Type of polymer & $\begin{array}{l}\text { Cycles for } \\
\text { optimum } \\
\text { cure }\end{array}$ & $\begin{array}{l}\text { Weight } \\
\text { increases }\end{array}$ & $\begin{array}{l}\text { Combined } \\
\text { sulfur }{ }^{1}\end{array}$ \\
\hline Natural.... & 2 & $\begin{array}{r}\text { Percent } \\
3.52\end{array}$ & $\begin{array}{l}\text { Percent } \\
2.31\end{array}$ \\
\hline $\mathrm{GR}-\mathrm{A} \ldots \ldots$ & 8 & 2.65 & 1. 14 \\
\hline Hycar OR-15 & 8 & 2. 52 & 1. 37 \\
\hline Hycar OR-25......... & 8 & 3. 58 & 2. 55 \\
\hline Hycar OS-10.... & 8 & 1. 93 & 1. 24 \\
\hline Hycar OS-20.... & 2 & 2. 14 & 1. 21 \\
\hline Hycar OS-30.......... & 4 & 1. 73 & 1.17 \\
\hline GR-S $\ldots \ldots$ & 8 & 4. 30 & 3. 08 \\
\hline GR-I & 128 & 5. 30 & 1. 12 \\
\hline GR-M & $>128$ & $>27.55$ & $>15.64$ \\
\hline
\end{tabular}

1 Based on parts per hundred parts of polymer.

\section{Discussion of Results}

As only about 0.2 percent weight increase was effected by either of the Peachey process gases alone, it is clearly indicated that there are no appreciable side reactions whereby one gas might act independently of the other to cause any significant increase in weight in the rubber. Therefore it is reasonably certain that any appreciable increase in weight on the dry basis is caused by a combination of the nascent sulfur, which is released by the interaction of the two gases within the specimen, with the unsaturated bonds of the rubber, plus any free sulfur that the sample is able to hold in solution or as a deposit on the surface. This reaction of the gases within the rubber samples, in addition to forming nascent sulfur, also produces water. Although it is quite possible that the quantity of moisture present in the samples or in the gases may have an effect on the rate of the vulcanizing reaction [3] no attempt was made to measure this amount because all of the samples were subjected to the same general conditions that should produce comparative results.

It is interesting to note that in the initial series of tests on natural rubber, as can be seen in figure 1 , a greater quantity of sulfur was taken up when the rubber had been compounded with zinc oxide and stearic acid, but that no further significant addition of sulfur was noted when an accelerator (mercaptobenzothiazole) and an ultra accelerator (zinc dimethyldithiocarbamate) were added. Several possible explanations may be suggested. The zinc oxide and the stearic acid may supply an accelerating effect that causes more sulfur to combine with the rubber in a given length of time, in effect speeding up the rate of cure. It may also be that the sulfur is merely displacing the oxygen of the zinc oxide to form zinc sulfide, which could readily account for the additional increase in weight. S. J. Peachey [6] believes that compounded rubber absorbs the gases more readily than pure rubber. As this phase was not of primary interest to this investigation, this problem was not probed deeply enough to ascertain the correct explanation. However, it is felt that these particular accelerators apparently had little or no influence on the amount of the sulfur added. St. Reiner [8], on the other hand, claims that certain organic accelerators speed up the reaction. Whether or not he too used a metallic oxide along with the accelerator, as is customary for hot curing, and mistakenly attributed the increase in 
$\mathrm{r}_{\text {ate }}$ of the sulfur addition solely to the presence of the accelerator is not known.

In some of the preliminary runs, it was noticed that there were variations in the amounts of sulfur taken up by the same polymer for a similar number of cycles in different series of runs. In these early runs the polymers may not have been sheeted as uniformly in thickness as in the later runs. As has already been mentioned, the amount of moisture present in the polymer may also have affected the rate of cure. However, this phase of the problem was not studied further, as the sole purpose of this investigation was merely to learn whether or not synthetic rubbers could be vulcanized by this method.

It should be pointed out that Hycar OS-20 and Hycar OS-30 cured at approximately the same rate, showing that the presence or absence of fatty acids in the butadiene-styrene type polymers is immaterial as far as the vulcanizing process is concerned (see fig. 3). The Hycar OS-10, having a higher styrene content than the Hycar OS-20, Hycar OS-30, or the GR-S, must have fewer double bonds, and consequently vulcanizes at a slower rate. GR-A and Hycar OR-15 were so similar in their rates of cure that the data had to be plotted as one and the same curve (see fig. 2). Hycar OR-25 has a lower acrylonitrile content than the Hycar OR-15 and the GR-A, and therefore, because of the larger number of double bonds, vulcanizes at a greater rate.

After a large number of cycles GR-I had taken up very little combined sulfur, probably because of the presence of relatively few double bonds in this polymer. This may explain why so much time is required for a good cure. The vulcanization of GR-M, which normally is vulcanized by the use of metallic oxides rather than of sulfur, also behaves differently in the Peachey process. Much sulfur was taken up by the GR-M, and even combined chemically with it, but an undercure was still obtained when over 15 percent of sulfur had combined.

By vulcanizing strips of rubber by the Peachey process, it was possible to show a very striking illustration of the influence that the direction of milling has on certain physical properties of the vulcanizate. Table 5 and figure 5 show that all of the specimens cut transverse to the direction of passage of the rubber between the mill rolls have a substantially higher degree of elongation and permanent set than those cut longitudinal to the direction of milling when subjected to the same relative stress. The shearing action produced by the difference in speeds of the two rolls of the mill partially stretches and aligns the molecules of the rubber. The specimens that are cut and vulcanized in the same direction as the partially elongated chains naturally will not stretch as much as those cut at right angles to the already stretched configurations under the same force.

TABLE 5. Effect of direction of milling on stress and set

\begin{tabular}{|c|c|c|c|c|c|c|}
\hline \multirow[b]{2}{*}{ Type of polymer } & \multirow{2}{*}{$\begin{array}{c}\text { Length } \\
\text { of } \\
\text { cycles }\end{array}$} & \multirow{2}{*}{$\begin{array}{l}\text { Weight } \\
\text { in- } \\
\text { crease }\end{array}$} & \multicolumn{2}{|c|}{ Elongation } & \multicolumn{2}{|c|}{ Permanent set } \\
\hline & & & $\begin{array}{l}\text { Longi- } \\
\text { tudi- } \\
\text { nal }\end{array}$ & $\begin{array}{l}\text { Trans- } \\
\text { verse }\end{array}$ & $\begin{array}{l}\text { Longi- } \\
\text { tudi- } \\
\text { nal }\end{array}$ & $\begin{array}{l}\text { Trans- } \\
\text { verse }\end{array}$ \\
\hline Natural _. & 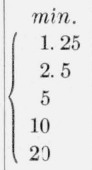 & $\begin{array}{c}\text { Percent } \\
1.16 \\
1.97 \\
3.18 \\
3.86 \\
4.29\end{array}$ & $\begin{array}{r}\text { Percent } \\
135 \\
122 \\
98 \\
88 \\
80\end{array}$ & $\begin{array}{r}\text { Percent } \\
203 \\
151 \\
121 \\
104 \\
90\end{array}$ & \begin{tabular}{|} 
Percent \\
4.8 \\
3.2 \\
1.6 \\
1.6 \\
1.6
\end{tabular} & $\begin{array}{r}\text { Percent } \\
8.8 \\
5.6 \\
4.8 \\
4.8 \\
4.8\end{array}$ \\
\hline
\end{tabular}

These same conclusions are drawn from some unpublished experiments performed several years ago by W. H. Smith and F. L. Roth of the National Bureau of Standards. They stretched a wide flat strip of raw rubber and vulcanized it while in the elongated state by the sulfur chloride method. Dumbbell specimens were cut from this vulcanized strip both in the direction of stretch and also at right angles to it. The specimens that were cut transverse to the direction of original stretch were softer and showed considerably greater values of ultimate elongation and tensile strength.

The authors are indebted to Eleanor F. Pangborn for making the many sulfur determinations necessary for the preparation of the tables given in this paper. The investigation resulted from an original suggestion by Harry L. Fisher, Office of Rubber Reserve. 


\section{References}

[1] Possibilities of the Peachey process, India Rubber World 62, 787 (1920).

[2] The perfected Peachey process, Rubber Age 19, 195 (1926).

[3] L. Hoch and H. Schmidt, The formation of sulfur from hydrogen sulfide and sulfur dioxide, Kautschuk 10, 82 (1934).

[4] F. Jacobs, The Peachey process, Caoutchouc and Gutta-Percha 26, 14506 (1929).
[5] A. T. McPherson, Vulcanization of GR-S by the Peachey process, Rubber Age 59, 323 (1946).

[6] S. J. Peachey, Lecture on cold vulcanization, India Rubber J. 63, 427 (1922).

[7] S. J. Peachey and A. Skipsey, New process for the vulcanization of rubber, J. Soc. Chem. Ind. Trans. 40, 5 (1921).

18] St. Reiner, Observations on the formation of sulfur from hydrogen sulfide and sulfur dioxide, Kautschuk 10, 128 (1934).

Washington, September 5, 1947. 